\title{
Affordable Heat: Lowering Vermont's Fuel Bills -- and Greenhouse Emissions
}

Carsey Institute - New England Center

October 29, 2008

Richard Cowart

The Regulatory Assistance Project

50 State Street, Suite 3

Montpelier, Vermont USA 05602

Tel: 802.223.8199

Fax: 802.223.8172
177 Water St. Gardiner, Maine USA 04345 Tel: 207.582.1135 Fax: 207.582.1176

Website:

http://www.raponline.org 


\section{Two Themes Today}

1. Vermont's "all-fuels/whole buildings" program for thermal efficiency $(S .209,2008)$

* Statewide goals, may triple Vermont Gas EE programs, extend WAP and electric EE programs

* New funding for liquid fuel efficiency: from RGGI \& ISO-NE Forward Capacity Market revenues -

* BUT: New revenue not adequate to meet adopted goals - no new tax $\$ \$$

* Comprehensive, not low income alone

\section{Efficiency and Climate Strategy}

* Top-down, price-driven GHG reduction is the expensive way to go !

* NOT "Cap and Give" or "Cap and Dividend"

* BETTER : "Cap and Invest" 


\section{Affordable Heat: The Challenge}

Fossil Fuel Bill: \$ 800M per year

up $\$ 340 \mathrm{M}$ in 4 years

Fossil fuels for buildings are VT's second-largest source of GHG emissions

Future risks of price increases and carbon

Vermont Annual Residential and Commercial Energy Expenditures for Fossil Fuels

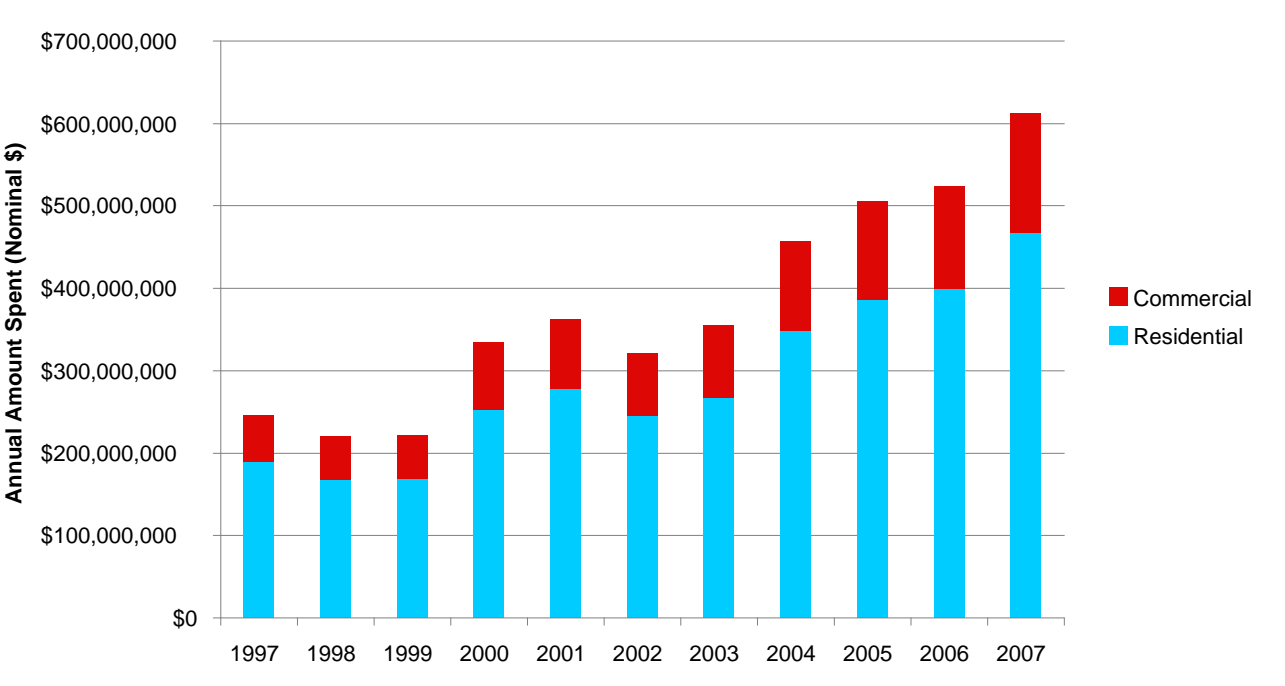
policy costs

Fuel dollars quickly leave Vermont 


\section{Framing: The High Cost of Importing Carbon}

Wholesale Fossil Fuel Expenditures

Total New England Fossil Fuel Expenditures in $2004=\$ 21$ Billion

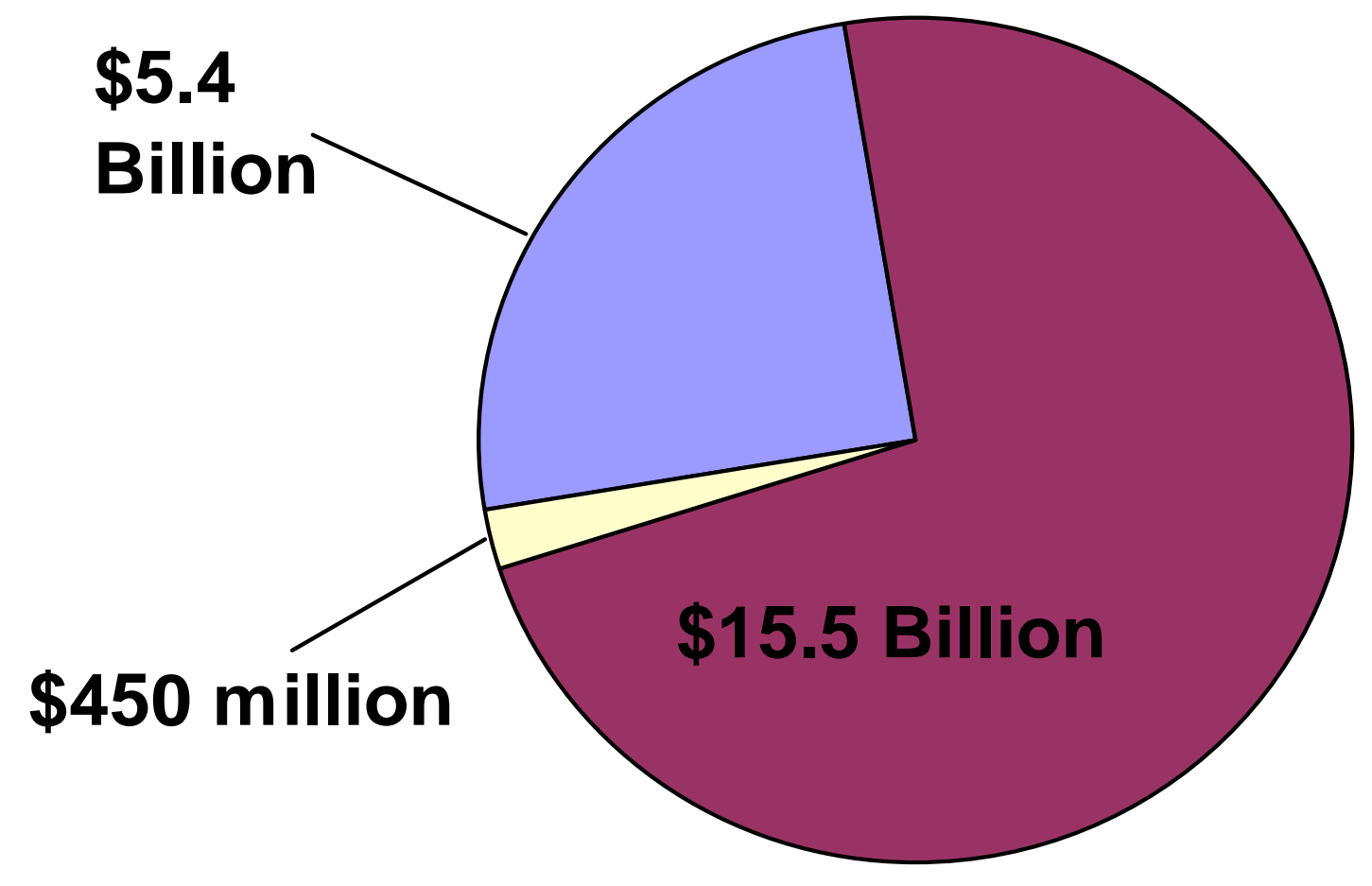

$\square$ Natural Gas

$\square$ Petroleum

$\square$ Coal 


\section{Framing: Affordable heat is a cost-effective investment opportunity}

Report recommended:

$20 \%$ of housing stock treated 2017 60,000

In treated $\mathrm{HH}$, lower fuel bills by average $\mathbf{2 5 \%}$

Fuel savings would exceed \$1.5 Billion from measures installed over 10 years

Reduce Vermont's annual fuel use by $6 \%$ by 2017

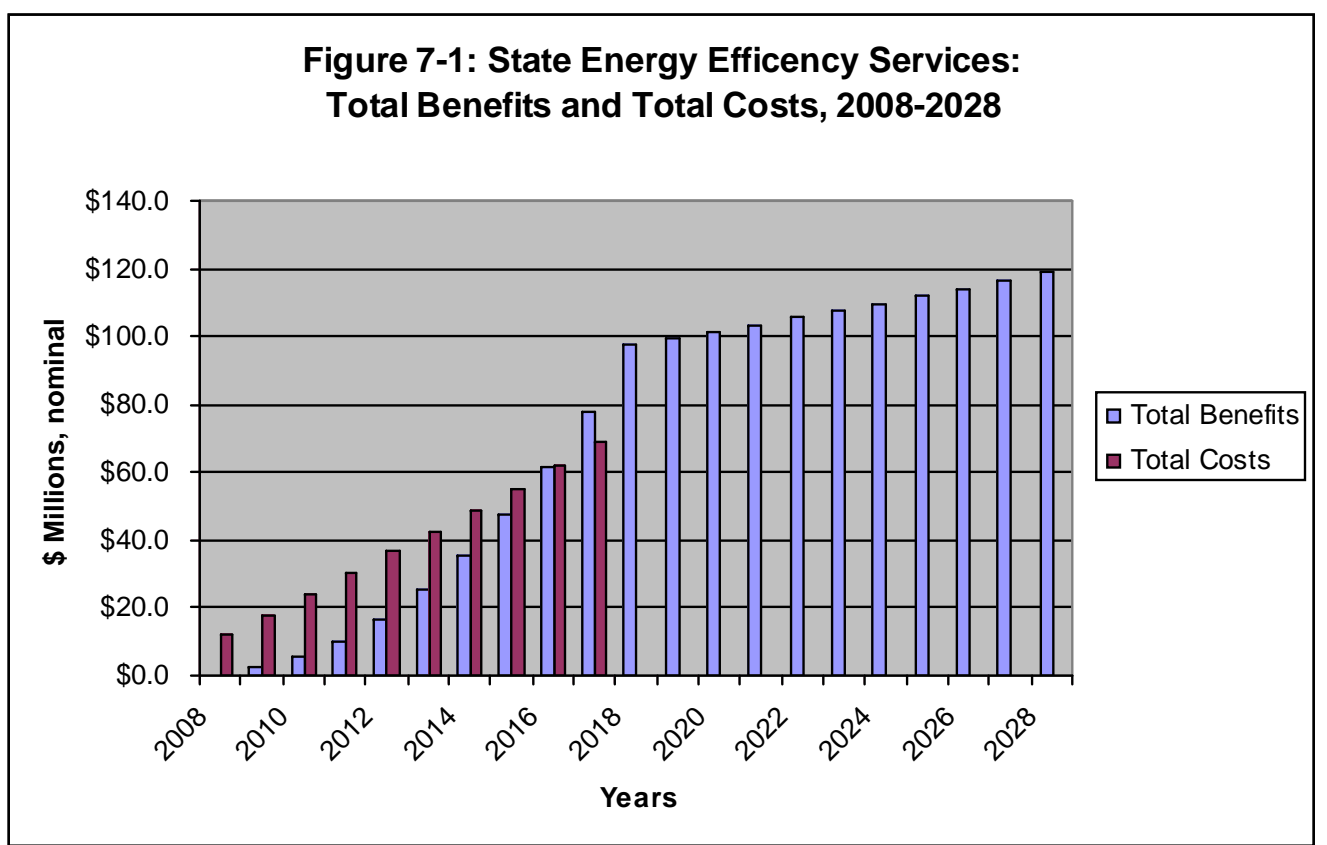

Save \$100 million per year 


\section{Goal: 60,000+ Buildings}

$>$ Low income Weatherization

$>$ Res and Comm Building Efficiency

$>$ New Construction

$>$ Vermont Gas

$>$ Plus effect of building energy codes

$>$ Total cost: $\$ 400$ million over ten years
Benefit/ Cost: 2.64

Considering Public and Private Costs

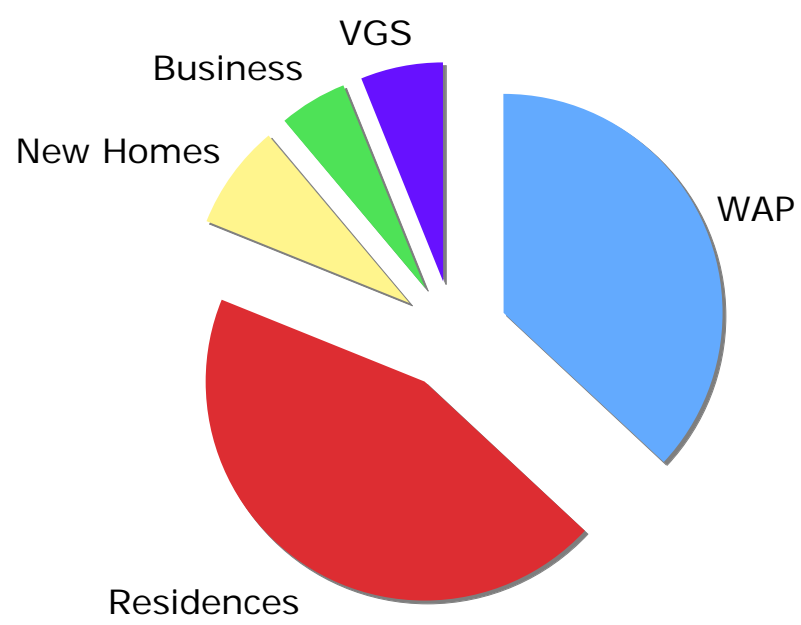

Phase in: 2300 buildings in 2008; 9600 buildings in 2017 
Proposed: Double the lowincome weatherization program

$>$ Need: 50,000 eligible low-income $\mathrm{HH}$

$>$ WAP today serves $\sim 1450$ units/year

$>$ Average fuel savings: $21 \%$ plus health, comfort, life safety, reduced public assistance \& bad debt. \$2 to $\$ 5$ saved for each dollar invested

$>$ Average cost/unit: $\sim \$ 5300$

$>$ Goal: ramp up to 3050 units/year by 2016

$>10$-year goal $=23,875$ units total 


\section{Funding Affordable Heat-- Where would $\$ 400$ million come from?}

$>\sim 50 \%$ Private capital leveraged with loans and incentives

$>$ Existing sources: Gross Receipts Tax, VGS and existing Efficiency Vermont: $\sim 25 \%$

$>$ RGGI and FCM revenues: $10 \%$

$>$ New public revenues needed (GRT increase or General Fund, etc.) 15\% 


\section{Vermont Energy Efficiency and Affordability Act $(S .209,2008)$}

$>$ Sets thermal efficiency goals (units and \%s)

$>$ Tightens building codes

$>$ Creates Fuel Efficiency Fund, administered by DPS and PSB, funded by RGGI allowance proceeds

$>$ Adds FCM \$ to Efficiency Vermont revenue pool for "whole buildings" EE

$>$ Encourages PSB and Vermont Gas to expand natural gas DSM

$>$ Studies (only) increase in Energy GR Tax

$>$ (Also: net metering, green pricing, renewables) 


\section{Resisting temptation}

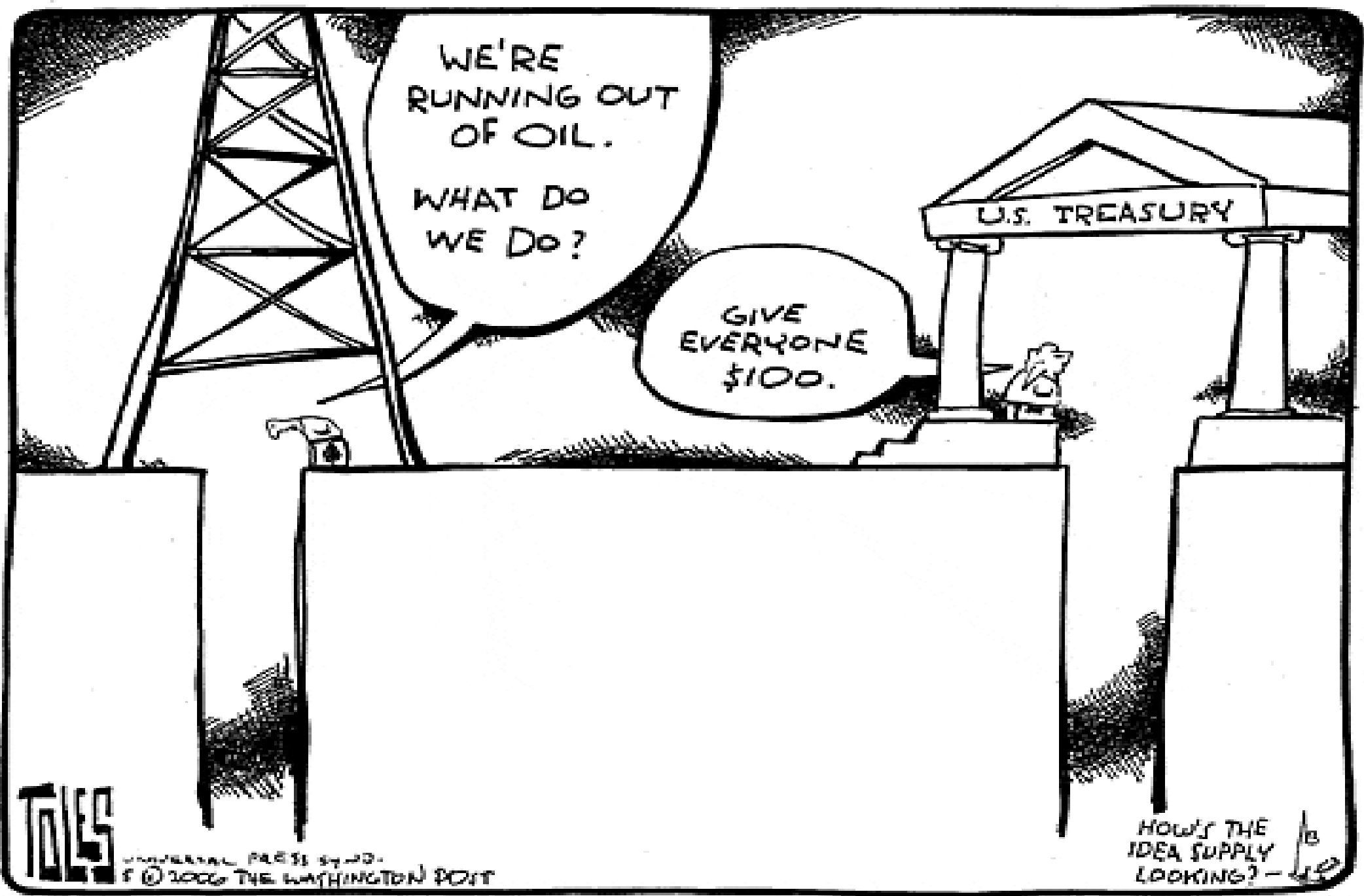

$5 \cdot 1 \cdot c$ 


\section{Theme 2: Reworking Climate Strategy}

> "Top down" cap and trade relying on price alone is more expensive, less likely to succeed than a portfolio-based policy menu (plus a cap);

$>$ Carbon allocation can accelerate cap/trade success, lower program costs - build EE into national programs;

$>$ State policies (EE, codes, portfolio mgt, RPS, etc. ) are crucial to success;

$>$ Low-income EE can serve both climate and equity goals. 


\section{Why carbon taxes and auctions create "high cost tons"}

$>$ Carbon price must be very high to save many tons (for gas to displace coal, etc.)

$>$ Fossil units almost always set the clearing price

$>$ Short-term clearing price provides the benchmark for longer-term and bilateral contracts

$>$ SO: Carbon penalty on sellers raises prices generally

$>$ Inframarginal rent a/k/a "windfall gains" to generators paid for by consumers 


\section{Problem \#1: Carbon taxes and auctions to sources can increase wholesale power prices with little effect on dispatch or emissions}

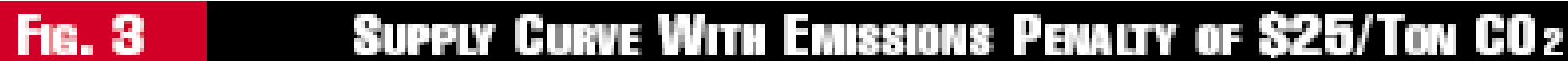

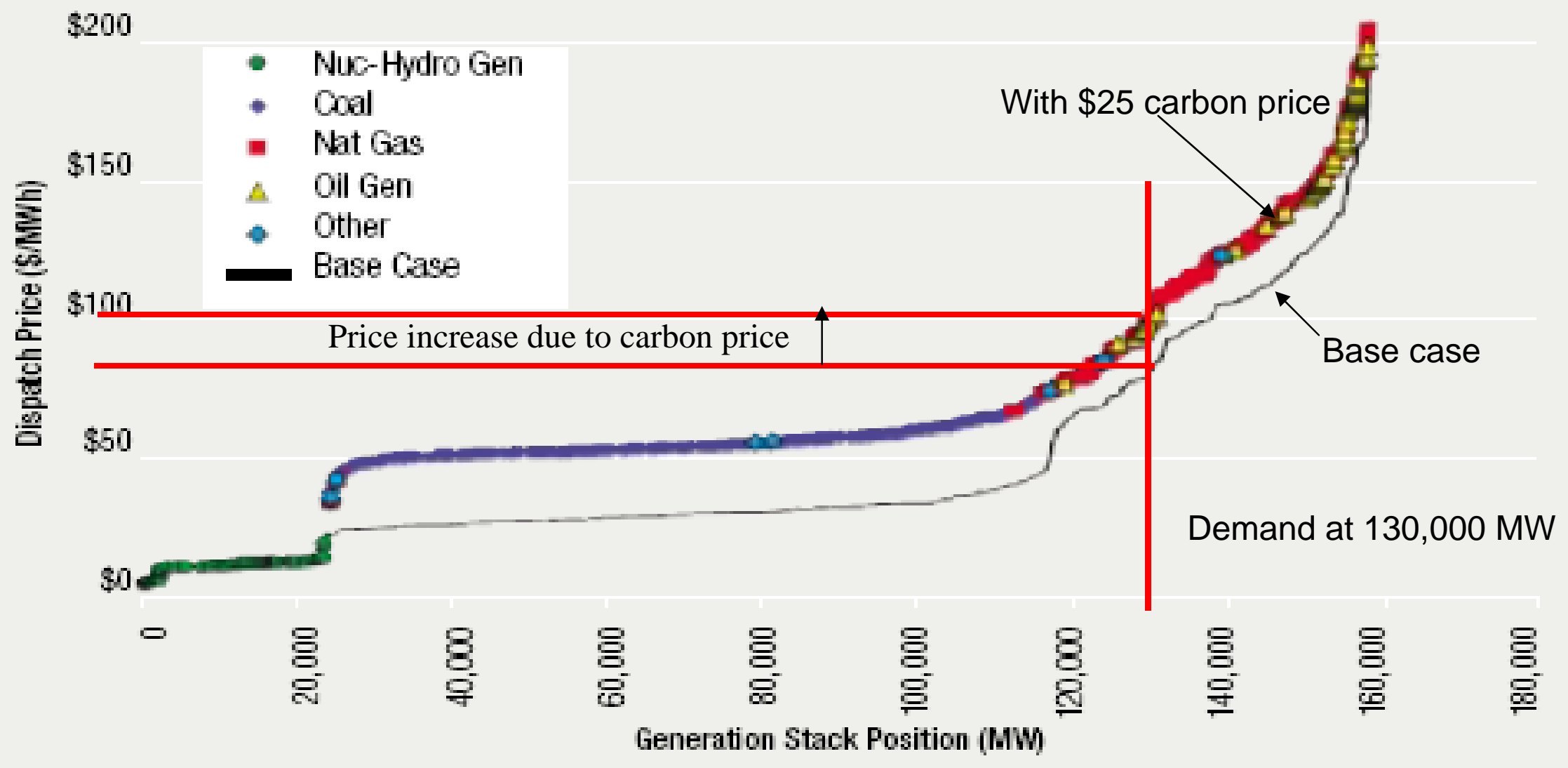

Source: "The Change in Profit Climate: How will carbon-emissions policies affect the generation fleet?"

Victor Niemeyer, (EPRI) -- Public Utilities Fortnightly May 2007 <some captions, demand and price lines added> 


\section{Americans need help when it comes to energy efficiency}
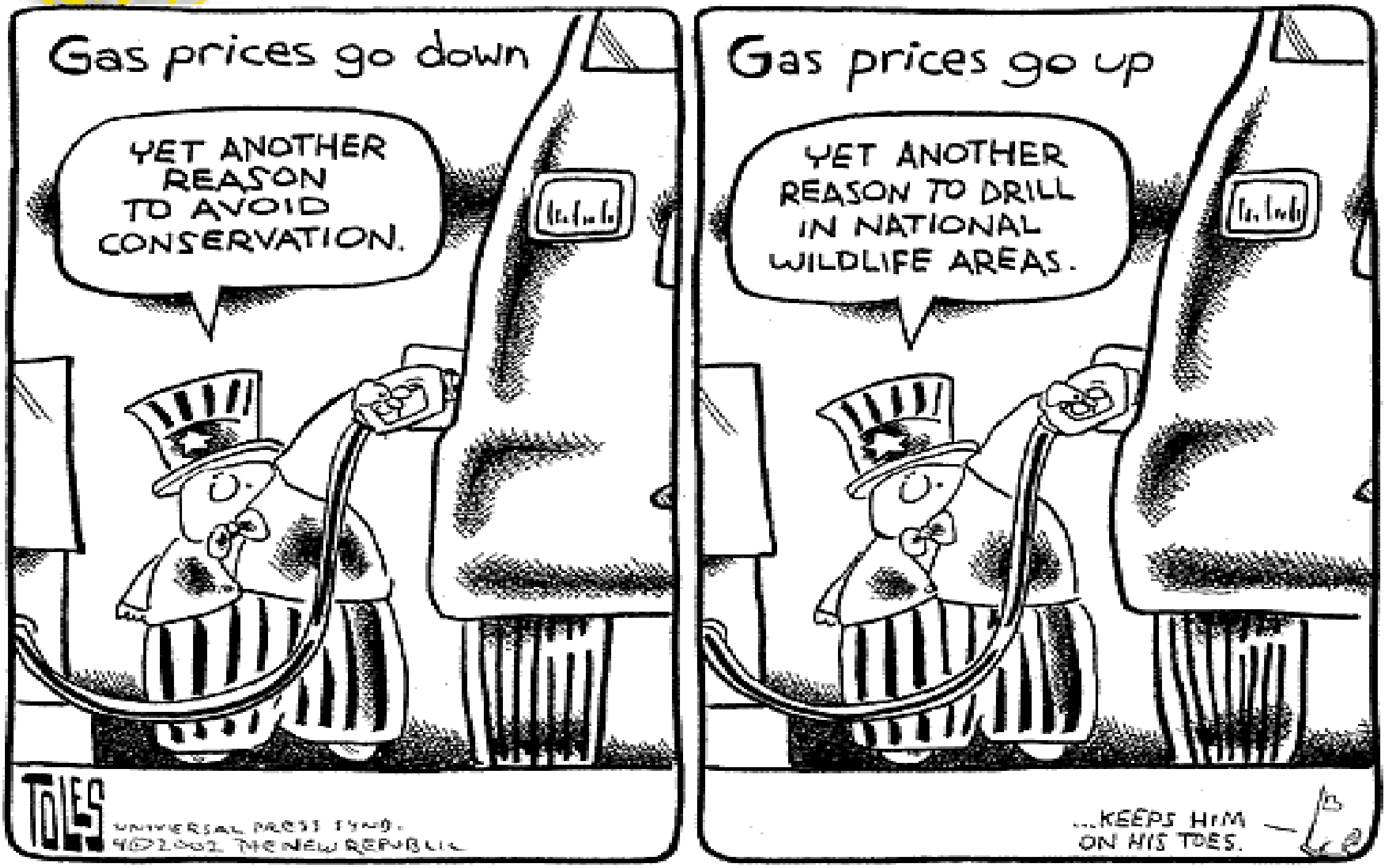

TWR $4 \cdot 6 B$ 


\section{Efficiency programs can save 7 times more carbon}

\section{per consumer \$ than carbon taxes}

Annual $\mathrm{CO}_{2}$ Emissions Saved by: Increasing Rates 3\%; and Increasing Rates 3\% to Fund Energy Efficiency (Ohio Example)

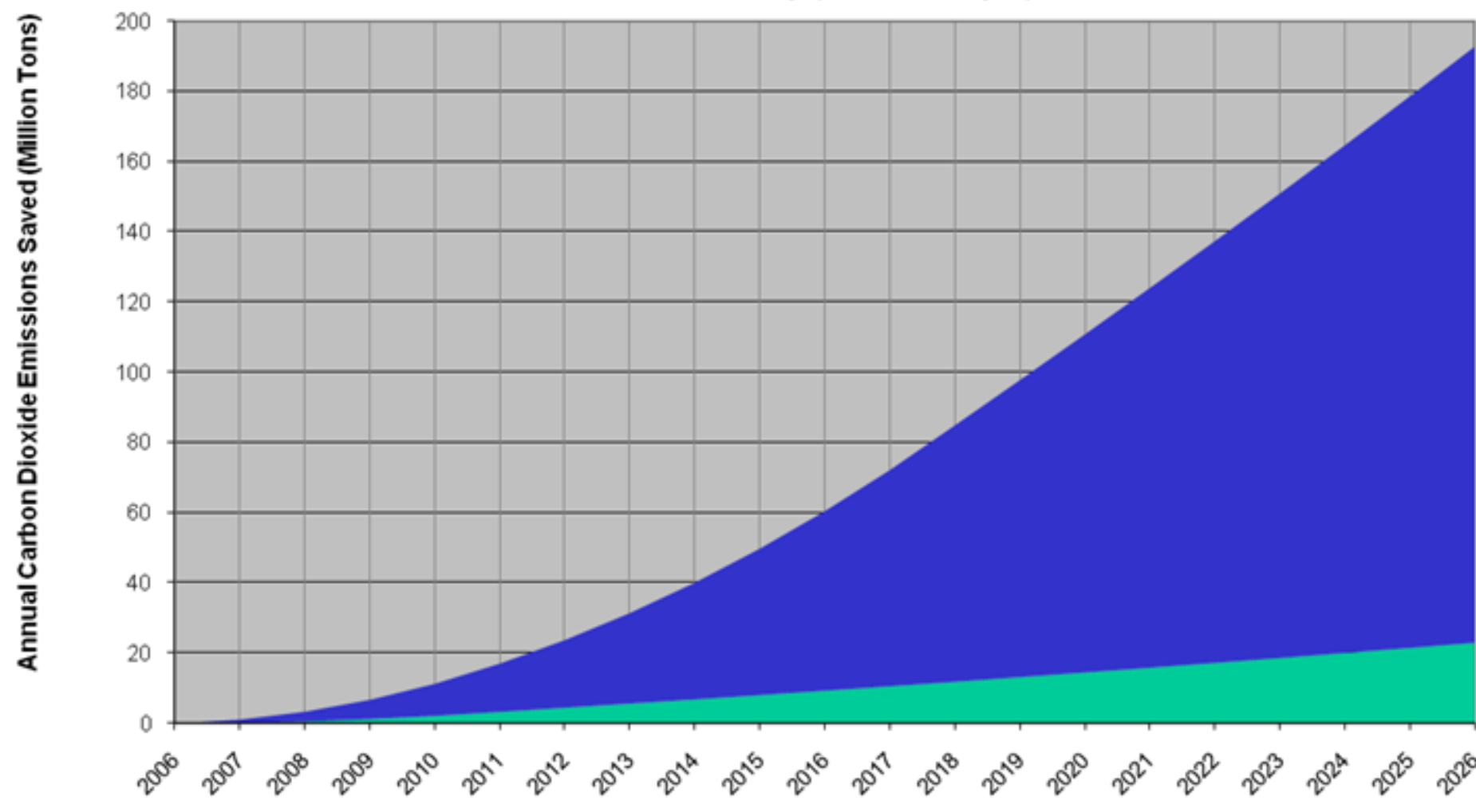

- Annual carbon dioxide emissions avoided from raising rates $3 \%$ and funding $E E$

= Annual carbon dioxide emissions avoided from raising rates $3 \%$

Cumulative $\mathrm{CO}_{2}$ emissions avoided from raising rates $3 \%$ and funding $E E$. 2006-2026: 1,557 million tons

Cumulative $\mathrm{CO}_{2}$ emissions avoided from raising rates $3 \%$.

2006-2026: 209 million tons 


\section{Response \#1: Efficiency is the low-cost "carbon scrubber"}

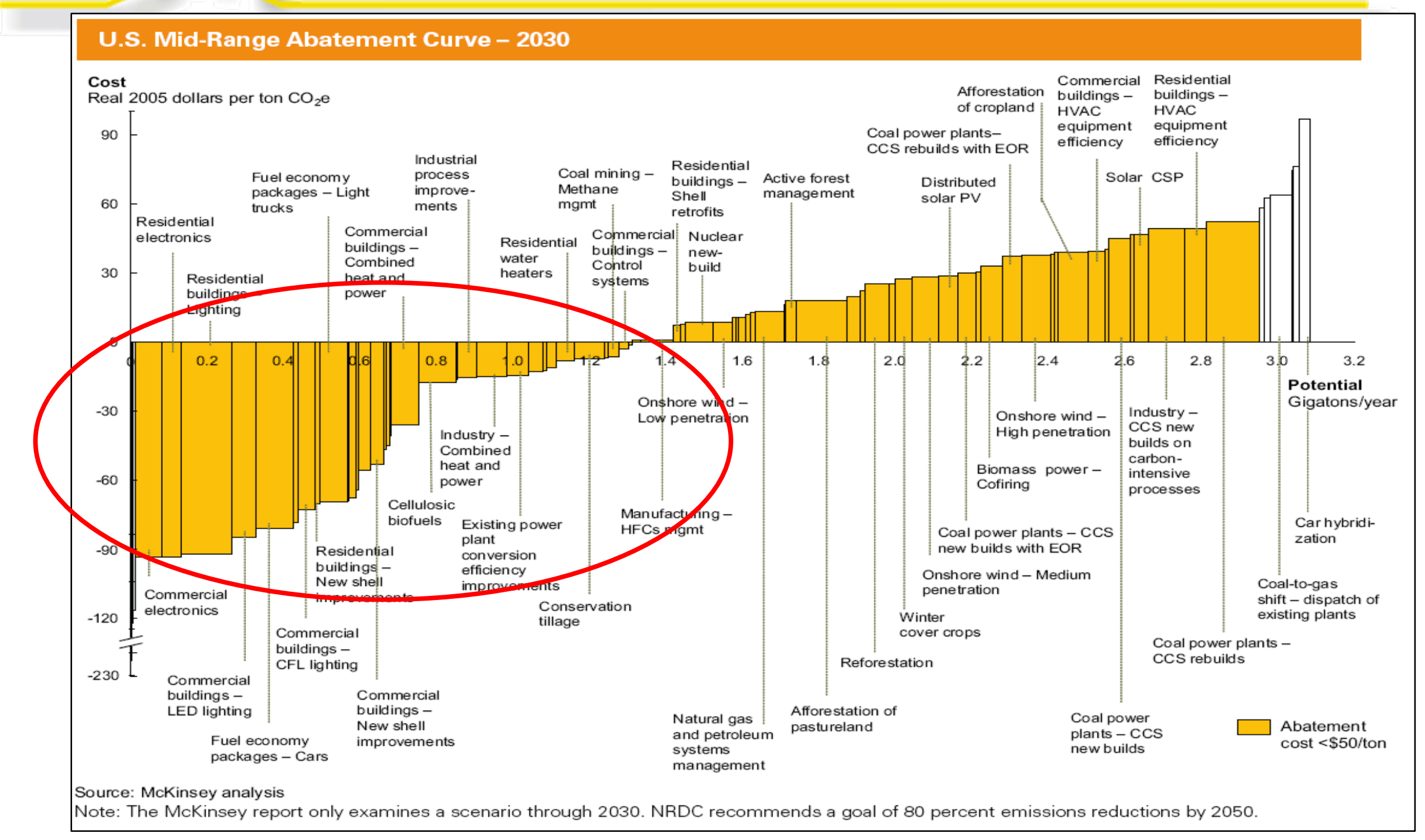


Lots of Low-hanging fruit: Efficiency Vermont Savings Yield Rates (MWh per $\$ 10,000$ invested)

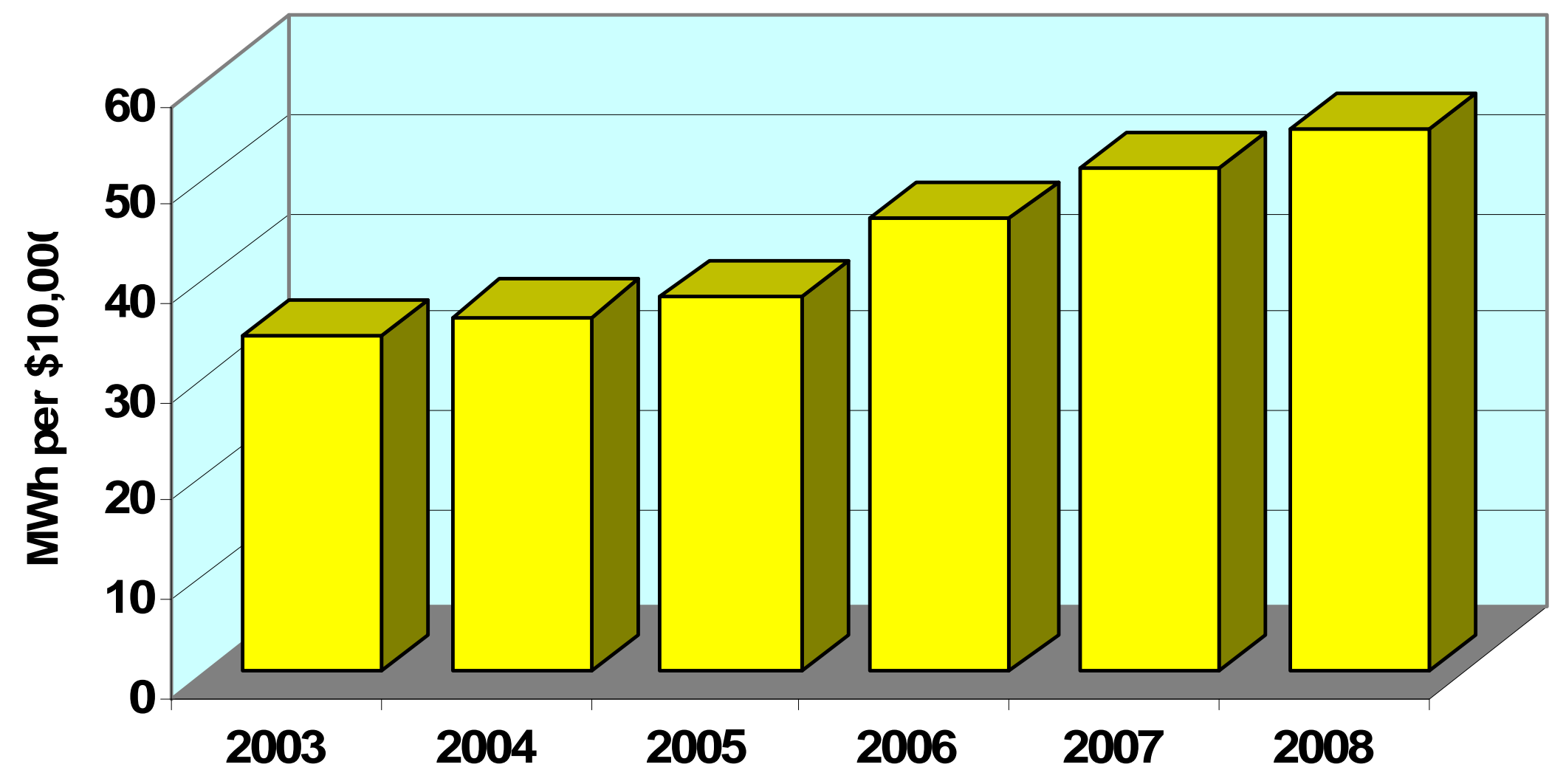




\section{Lessons for national legislation -- Carbon}

credit allocation can mobilize efficiency

$>$ Key point: A carbon program that directly mobilizes end use efficiency will cost less and achieve more than one that focuses only on smokestacks.

* Lower cost attainment - that's the whole point of cap and trade in the first place

$>$ Cap/trade techniques can tap the carbon value of efficiency:

* Consumer allocation (RGGI region)

- Load-side caps - carbon budgets for utility companies, akin to Renewable Portfolio Standards

* National Efficiency Allocation (RAP \& ACEEE proposal) 


\section{National Efficiency Allocation*}

D Proposal: Allocate a pool of carbon allowances to states or LSEs to promote end-use efficiency

$>$ Allocation should be performance-based:

* Reward actual EE success, not expenditures or particular policy approaches

$>$ How to measure EE success?

* Key feature: \% improvement compared to a baseline

* Each state (or LSE) has its own baseline

* Indiana compared to Indiana, not Indiana compared to California

* Sets up a "virtuous circle" of competition among entities those who improve faster earn a bigger fraction of the pool.

*As proposed by R Cowart (RAP) and S Nadel (ACEEE) March 2008 - comments and improvements are welcome 


\section{Is allocation just "distributional"? DC version: allocation for 60 votes}

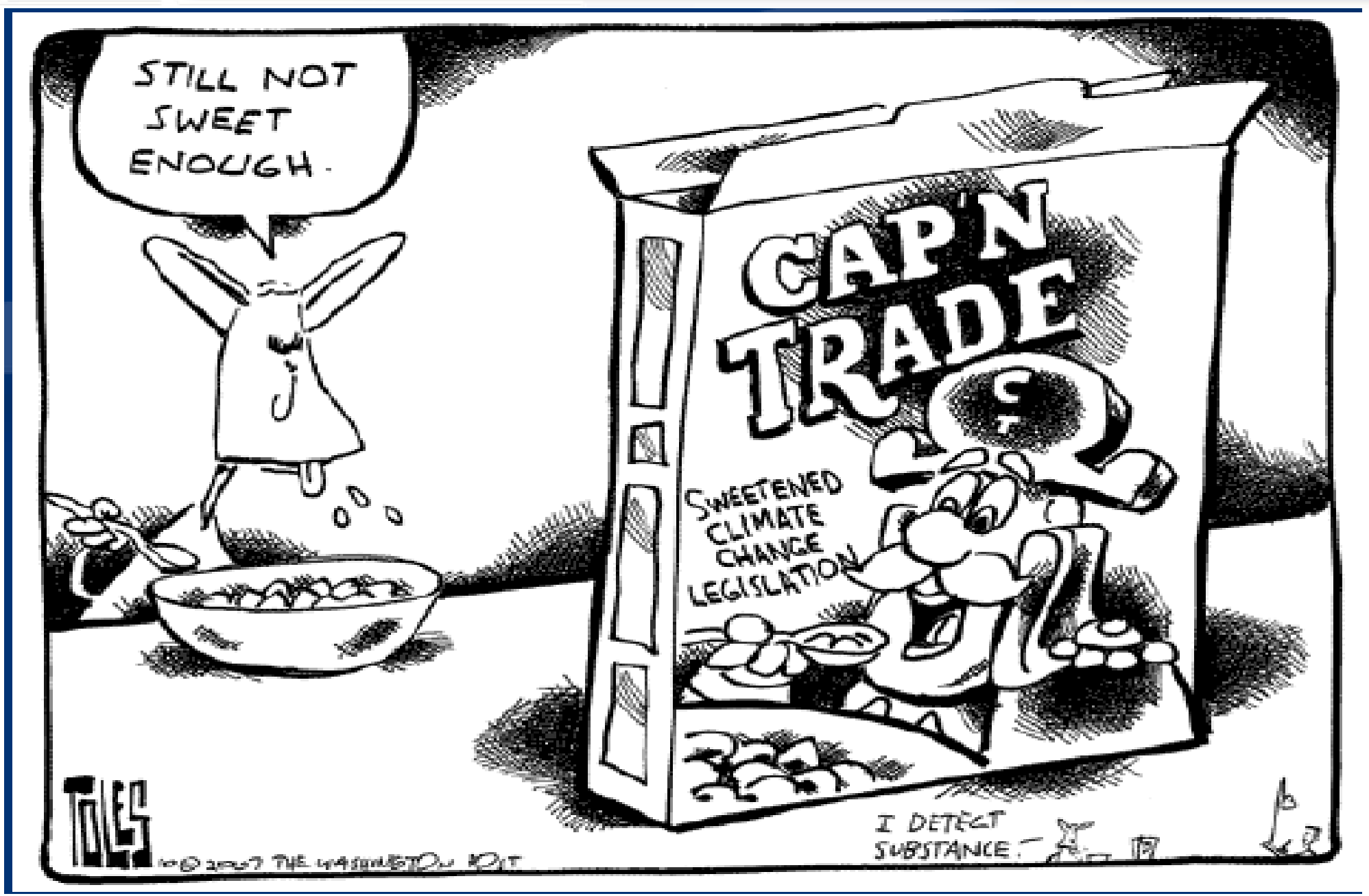




\section{For more information...}

- "Affordable Heat: A Whole-Buildings Efficiency Service for Vermont Families and Businesses"

(RAP study for Vermont Legislature January 2008)

- Carbon Caps and Energy Efficiency: The Marriage of Need and Potential (Energy Efficiency Finance Forum April 2007)

- "Power System Carbon Caps: Portfolio-based Carbon Management" (NREL Carbon Analysis Forum November 2007)

- "Why Carbon Allocation Matters - Issues for Energy Regulators" (March 2005)

- "Another Option for Power Sector Carbon Cap and Trade Systems - Allocating to Load" (May 2004)

Richard Cowart, Regulatory Assistance Project

Posted at www.raponline.org

Email questions to RAPCowart@aol.com 